\title{
LOWER CANINE MALPOSITIONS IN THE PERIOD OF ERUPTION: INCIDENCE AND RELATION WITH UPPER CANINE MALPOSITIONS
}

\author{
Arnautska H. ${ }^{1}$, V. Krumova ${ }^{2}$ \\ ${ }^{1}$ Department of Prosthetic Dental Medicine and Orthodontics, Faculty of Dental Medicine, \\ Medical University of Varna, \\ ${ }^{2}$ Department of Orthodontics, Faculty of Dental Medicine, Medical University of Sofia
}

\begin{abstract}
Times of eruption and final formation of the apices of lower canines precede these of the upper canines by approximately 2 years. Deviations in time of eruption and position of the lower canines may indicate disturbances in the formation of orthognathic occlusion. The objective of this epidemiological study was to examine the incidence of eruption deviations, or the tendency to impaction of lower canines as well as the incidence of simultaneous eruption deviations of the lower and upper canines in the range of 9 to 18 years of age. In 705 out of a total of 907 children, various deformities were found out. In $201(28,51 \%)$ children, canine eruption deviations were observed either in the upper, or in the lower jaw, or in both jaws. In $56(27,86 \%)$ of these children, deviations in lower canine position and in both upper and lower canine positions were established. These results show that in permanent dentition, there is a significant increase of the troubles related with lower canine malposition. In $20(57,14 \%)$ children, malpositions of the lower canines only were observed, while in 10 $(28,57 \%)$ ones, malpositions of both upper and lower canines were found. In late mixed dentition, canine deviations in both upper and lower jaws were more common. The incidence of deviations in canine position for both jaws was the highest in class I according to the Angle's classification, i.e., in 48 children (in 85,71\% of the cases). In conclusion, the early detection of disturbances in eruption and position of lower canines is of crucial importance for the formation of normal occlusal proportions and thus an essential precondition for dentition functionality and aesthetics. Early primary and secondary prophylactic measures may be of significant benefit for the regularity of lower canine eruption.
\end{abstract}

Key words: lower canines, malposition, malocclusion, epidemiological study, children

\section{INTRODUCTION}

Upper and lower canines are of essential importance for the formation of orthognathic occlusion. Their presence in the dental arch and regular occlusal proportions determine the ideal aesthetics of dental smile, correct masticatory movements and continuous functional fitness of dentition. In normally developing dentition, the lower canines erupt at about 9-10 years of age and precede the eruption of the upper canines by approximately 2 years. The diagnosis of lower canine impaction is suggested in case of delayed lower canine eruption in the already formed permanent dentition, or in the absent probability for eruption established during a clinical examination and radiologically verified.

Address for correspondence:

H. Arnautska, Dept. of PDM and Orthodontics,

Faculty of Dental Medicine, Medical University of Varna

150, Tcar Osvoboditel Blvd

e-mail: tineia@abv.bg
The incidence rate of lower canine impaction is lower than that of the upper canines and varies from $0,22 \%$ (7) up to $0,44 \%(5)$.

Migration is a rare phenomenon typical of lower canines only. It is due to impacted canines which have crossed the median line with more than a half of their crown lengths (8). According to different authors, the incidence of transmigration is extremely low - between $0,14 \%$ and $0,31 \%$ (1-3). Usually, this is unilateral although bilateral cases have also been reported. It is slightly more common in women - between 1,6:1 (10) and 1,22:1 (5) and occurs more often in the left than in the right side (10).

The reasons for eruption disturbances and canine impaction may be local or general. The local factors include existing follicular cyst, excessive number of teeth, tumour process, or absence of space in the dental arch due to a premature deciduous canine loss, dental-jaw incongruity, or persisting deciduous canines. General factors may involve hereditary or endocrine disorders as well as impaired eruption due to a trauma or fracture with tooth follicle displacement, a surgical intervention in the region of the mandibular body, the long path of eruption, which should be passed by the lower 
Lower canine malpositions in the period of eruption: incidence and relation with upper canine malpositions

canine along with the compactness of the sutureless mandibular bone enabling canine migration $(3,6,9)$.

Usually, impacted or migrated canines are not associated with any patient's complaints. The can be diagnosed on an X-ray examination on the occasion of orthodontic or prosthetic treatment.

The objective of this epidemiological study was to examine the incidence of eruption deviations, or the tendency to
An eventual correlation between canine deviations towards sagittal deformations in the children of this group was looked for, too.

The analysis of the results covered the age groups of late mixed (9-12 years of age) dentition and permanent (12-18 years of age) one. Times of eruption of the upper and lower canines are presented in Table 1 .

The existing canine malpositions in the late mixed (9-12

Table 1. Distribution of the children with delayed eruption according to Angle's classification ( $n=313)$

\begin{tabular}{|c|c|c|c|c|c|c|c|c|}
\hline \multirow{3}{*}{ Age groups } & \multicolumn{6}{|c|}{ Delayed eruption } & \multirow{2}{*}{\multicolumn{2}{|c|}{ Total }} \\
\hline & \multicolumn{2}{|c|}{ I dental class } & \multicolumn{2}{|c|}{ II dental class } & \multicolumn{2}{|c|}{ III dental class } & & \\
\hline & $\mathrm{n}$ & $\%$ & $\mathrm{n}$ & $\%$ & $\mathrm{n}$ & $\%$ & $\mathrm{n}$ & $\%$ \\
\hline 9-12 years & 18 & 32,14 & 3 & 5,36 & - & - & 21 & 37,50 \\
\hline $12-18$ years & 30 & 53,57 & 5 & 8,92 & - & - & 35 & 62,50 \\
\hline total & 48 & 85,71 & 8 & 14,29 & - & - & 56 & 100,00 \\
\hline
\end{tabular}

impaction of lower canines as well as the incidence of simultaneous eruption deviations of the lower and upper canines in the range of 9 to 18 years of age.

\section{MATERIAL AND METHODS}

We performed an epidemiological study in order to monitor the eruption and formation of occlusal proportions (4). The examinations were based on randomisation of a total number of 907 children aged between 9 and 18 years from two schools in Varna city. We followed-up canine development and eruption within the different age groups of late mixed and permanent dentitions. Times of deciduous tooth replacement by permanent teeth were estimated. Occlusal proportions and eventual relationship between the eruption disturbances of upper and lower canines were studied.

A statistical analysis of the obtained data was performed by using the SPSS 5.0 statistical software for Windows. The $\chi^{2}$ test was used for comparing the qualitative variables and the correlation analysis was applied for studying the inter-variable correlations and determining the inter-variable relations. Student's $t$-test was used for comparative analysis and defining any statistical differences between the studied variables.

\section{RESULTS AND DISCUSSION}

Normal development of dental arches and occlusion was found out in $202(22,27 \%)$ of all the examined children. In the rest $705(77,73 \%)$ ones, eruption deviations and disturbances in occlusal proportions were observed. In 201 children (in $28,51 \%$ of the cases) with various deformities, canine eruption deviations were observed either in the upper, or in the lower jaw, or in both jaws. In $56(27,86 \%)$ of these children, deviations in lower canine position and in both upper and lower canine positions were found out. years of age) dentition for the mandible only and for both jaws are presented in Table 2. In this age group, lower canine eruption troubles were diagnosed in 7 children (in $33,3 \%$ of the cases) with class I according to the Angle's classification, while simultaneous upper and lower canine eruption problems were established in 11 children (in $52,3 \%$ of the cases). In class II cases, 3 children (in 14,29\% of the cases) presented with canine eruption problems in the mandible or simultaneously in both jaws.

Table 2. Distribution of lower canine and of both lower and upper canine malpositions in late mixed dentition

\begin{tabular}{||l|c|c|c|c|c|c||}
\hline \multirow{2}{*}{$\begin{array}{l}\text { Dental } \\
\text { class }\end{array}$} & \multicolumn{2}{|c|}{ Lower canines } & \multicolumn{2}{|c|}{$\begin{array}{c}\text { Lower and } \\
\text { upper canines }\end{array}$} & \multicolumn{2}{||}{ Total } \\
\cline { 2 - 7 } & $\mathrm{n}$ & $\%$ & $\mathrm{n}$ & $\%$ & $\mathrm{n}$ & $\%$ \\
\hline I & 7 & 33,33 & 11 & 52,38 & 18 & 85,71 \\
\hline II & 1 & 4,76 & 2 & 9,52 & 3 & 14,29 \\
\hline III & - & & - & & - & \\
\hline total & 8 & 38,10 & 13 & 61,90 & 21 & 100,00 \\
\hline \hline
\end{tabular}

Adhering to the same indices, canine malpositions in the permanent dentition (12-18 years of age) were found out in a total number of 35 children. These results are presented in Table 3.

In permanent dentition, there is a significant increase of the problems related with lower canine malposition. They were more pronounced in class I cases. In 20 children (in 57, 14\% of the cases), malpositions of the lower canines only were observed, while in 10 children (in $28,57 \%$ of the cases), there were malpositions of both upper and lower canines. In class II, there was a significantly smaller number of malpositions. A lower canine malposition existed in 3 children (in $8,57 \%$ of the cases ) but canine malpositions in both jaws - in two children (in 5,71\% of the cases). 
Table 3. Distribution of lower canine and of both lower and upper canine malpositions in permanent dentition

\begin{tabular}{||l|c|c|c|c|c|c||}
\hline \hline \multirow{2}{*}{$\begin{array}{l}\text { Dental } \\
\text { class }\end{array}$} & \multicolumn{2}{|c|}{ Lower canines } & \multicolumn{2}{|c|}{$\begin{array}{c}\text { Lower and } \\
\text { upper canines }\end{array}$} & \multicolumn{2}{|c||}{ Total } \\
\cline { 2 - 7 } & $\mathrm{n}$ & $\%$ & $\mathrm{n}$ & $\%$ & $\mathrm{n}$ & $\%$ \\
\hline I & 20 & 57,14 & 10 & 28,57 & 30 & 85,71 \\
\hline II & 3 & 8,57 & 2 & 5,71 & 5 & 14,29 \\
\hline III & - & & - & & - & \\
\hline total & 23 & 65,71 & 12 & 34,29 & 35 & 100,00 \\
\hline \hline
\end{tabular}

In class III cases, no deviations in canine position or eruption were found out for both age groups. The comparative analysis of the correlation between lower canine position deviations and dentition type shows a statistically reliable difference $\left(\chi^{2}=4,05 ; p<0,05\right)$. In permanent dentition, only lower canine deviations were more frequent $(65,71 \%)$, while in late mixed dentition, both upper and lower canine deviations were more common $(61,90 \%)$ (Fig. 1).

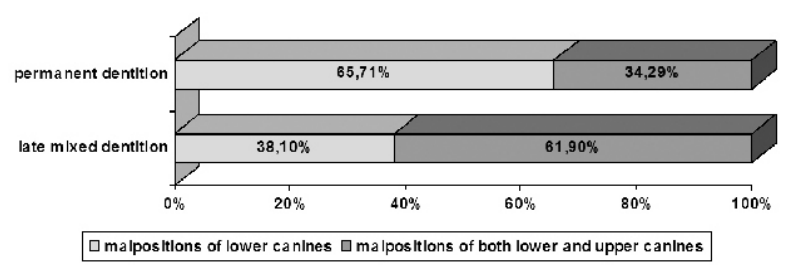

Fig. 1. Percentage distributions of lower canine and of lower and upper canine malpositions in late mixed and permanent dentitions

There is a moderate correlation between the dentition type and the malposition type $(\mathrm{r}=-0,27 ; \mathrm{p}<0,05)$. The coefficient of determination shows that the type of dentition has an impact on the presence of the specific type of malposition in $7,29 \%$ of the children.

This finding supports the need of performing early prophylaxis related with timely removal of the etiological factors in order to normalize dental arch development.

It is evident that the incidence rate of deviations in canine position for both jaws is the highest in class I according to the Angle's classification, i.e., in $48(85,71 \%)$ of the children.

The examinations of sagittal deviations fail to demonstrate any statistically reliable difference. Therefore, they do not exert any essential effect on the canine impaction. No relation has been found out between the type of dentition and the dental class during the distribution of canine deviations.

\section{CONCLUSION}

Our results enable us to draw the following conclusions:

1. Lower canine malpositions are not related with the dental class, which determines the sagittal deviations in the occlusion. These are common in class I as there are normal occlusal relations to the sagittal direction, thus ensuring the aesthetic and functional dentition fitness.

2. The significant number of lower canine eruption problems (in 31 children or in 55,35\% of the cases) of both age groups shows that this disorder alone is commonly presented. This fact is of importance for the formation of normal occlusal relations.

3. Deviations in lower canine eruption and in both upper and lower canine eruption in almost one-third (27,86\%) of the total number of the children under examination with canine malposition or eruption retardation justify the need of early proventive measures.

Therefore, early diagnosis of lower canine eruptive and positional deviations is of crucial importance for the formation of normal occlusal relations and thus an essential precondition for the functional and aesthetic dentition fitness. Early primary and secondary prophylactic measures may be of significant benefit for the regularity of lower canine eruption. The high incidence rate of eruption deviations in both jaws is an indicator for the need of prevention as soon as the early mixed dentition is formed.

\section{REFERENCES}

1. Aktan, A. M., S. Kara, F. Akgünlü, S. Malkoç. The incidence of canine transmigration and tooth impaction in a Turkish subpopulation.- Eur. J. Orthod., 32, 2010, No 5, 575-581.

2. Alaejos-Algarra, C., L. Berini-Aytes, C. Gay-Escoda. Transmigration of mandibular canines: report of six cases and review of the literature.Quintes. Int., 29, 1998, No 6, 395-398.

3. Aras, M. H., M. C. Büyükkurt, Ü. Yolcu, Ü. Ertaş, E. Dayi. Transmigrant maxillary canines.Oral Surg., Oral Med., Oral Pathol., Oral Radiol. Endodontol., 105, 2008, No 3, e48-e52.

4. Arnautska, H., V. Krumova. Epidemiological study of dental status and permanent canine eruption in children and adolescents aged 7 to 18 years.- Probl. dent. med. (Sofia), 37, 2011, No 2, 56-60 (in Bulgarian).

5. Aydin, U., H. H. Yilmaz, D. Yildirim. Incidence of canine impaction and transmigration in a patient population.- Dentomaxillofac. Radiol., 33, 2004, No 3, 164-169.

6. Camilleri, S., E. Scerri. Transmigration of mandibular canines - a review of the literature and a report of five cases.- Angle Orthod., 73, 2003, No 6, 753-762.

7. Grover, P. S., L. Lorton. The incidence of unerupted permanent teeth and related clinical cases.Oral Surg. Oral Med. Oral Pathol., 59, 1985, No 4, 420-425.

8. Javid, B. Transmigration of impacted mandibular cuspids.- Int. J. Oral Surg., 14, 1985, No 6, 547-549.

9. Joshi, M. R. Transmigrant mandibular canines: a record of 28 cases and a retrospective review of the literature.- Angle Orthod., 71, 2001, No 1, 12-22. 
Lower canine malpositions in the period of eruption: incidence and relation with upper canine malpositions

10. Sumer, P., M. Sumer, B. Ozden, F. Otan.

Transmigration of mandibular canines: a report of six cases and a review of the literature.- $J$. Contemp.

Dent. Pract., 8, 2007, No 3, 104-110. 